\title{
Measurement and meaning of head movements in everyday face-to-face communicative interaction
}

\author{
ANDREAS ALTORFER, STEFAN JOSSEN, OTHMAR WÜRMLE, \\ MARIE-LOUISE KÄSERMANN, KLAUS FOPPA, and HEINRICH ZIMMERMANN \\ University of Bern, Bern, Switzerland
}

\begin{abstract}
Methodological approaches in which data on nonverbal behavior are collected usually involve interpretative methods in which raters must identify a set of defined categories of behavior. However, present knowledge about the qualitative aspects of head movement behavior calls for recording detailed transcriptions of behavior. These records are a prerequisite for investigating the function and meaning of head movement patterns. A method for directly collecting data on head movement behavior is introduced. Using small ultrasonic transducers, which are attached to various parts of an index person's body (head and shoulders), a microcomputer determines receiver-transducer distances. Three-dimensional positions are calculated by triangulation. These data are used for further calculations concerning the angular orientation of the head and the direction, size, and speed of head movements (in rotational, lateral, and sagittal dimensions). Further analyses determine relevant changes in movements, identify segments of movements, and classify the quantifications of movement patterns. The measured patterns of nonverbal behavior can be accurately related to features of verbal communication and other time-related variables (e.g., psychophysiological measures). To estimate the possible meanings of behavioral patterns, a heuristic is proposed that includes the situational context as the basis of interpretation.
\end{abstract}

\section{Movement Notation: "Indirect" Observation or "Direct" Measurement}

Conducting empirical research in the area of nonverbal behavior requires reliable methods of measuring the behavior evidenced by participants in a conversation. Both Wallbott (1980) and Rosenfeld (1982) distinguish between two different approaches to measuring nonverbal behavior. First, indirect, or observational, methods rely on subjectively applied operational definitions to identify parameters of nonverbal behavior. Since the researchers are usually the ones who do the observing, they are an integral part of the coding process, which is influenced by their interpretations of the nonverbal aspects of behavior. The researchers' ability to judge nonverbal behavior appropriately can be improved with the help of methods that ensure interpretations that are more objective. For instance, when one is videotaping nonverbal behavior in human social interaction, reference points (a coordinate system with adjustable $x / y$-axes) can be assigned to compare definable points of the body frame-by-frame and to code position changes in quantitative terms (see Wallbott, 1980).

Parts of our research have been funded by grants from the Swiss National Science Foundation (Projects 1114-043635.95/1 and 1113$051050.97 / 1$ ). In addition, we thank Nicole Gilgen for her assistance in various sections of the analysis (partner in interaction task, transcription of verbal communication, timing-structure of verbal communication, etc.). Correspondence concerning this article should be addressed to A. Altorfer, Department of Psychiatric Neurophysiology, University of Bern, Bolligenstrasse 111, CH-3000 Bern 60, Switzerland (e-mail: altorfer@puk.unibe.ch).
Second, whereas indirect methods of measuring movement behavior rely on an "observational device," direct methods record nonverbal behavior without interpretative procedures. However, direct methods of measuring nonverbal behavior involve attaching sensors to the index person's body (reflectors, electrodes, etc.) that record movements with high resolution power but tend to cause discomfort (see Tryon, 1991). Examples of such measurement methods include electromyograms, tremormeters, infrared detectors, and goniometers (see Hadar, 1991; Hadar, Steiner, Grant, \& Rose, 1984). These technical solutions yield a measurement of global behavior (e.g., motionless or in motion) or of selected aspects of nonverbal behavior patterns (e.g., frequency of movements, muscle contractions in separate parts of the body, or shifts of head postures) that restricts their applicability to common questions in the field of nonverbal communication. Indirect instruments for measuring nonverbal behavior counteracted the discomfort that previously accompanied the use of direct methods. The indirect observational methods include descriptive behavioral rules (e.g., Frey, Hirsbrunner, Pool, \& Daw, 1981; Frey \& Pool, 1979), the appraisal of predefined properties for forming an impression (e.g., Rosenthal, 1982), or functional classifications of behavioral elements (e.g., Ekman \& Friesen, 1969).

\section{Methodological Limitations}

Coding of behavior. Even the proponents of indirect methods recognize the limitation of these procedures (Rosenfeld, 1982). According to Frey and Pool (1979), various 
strategies for data reduction are employed, usually at the time raw data collection is initiated. First, generic terms are used to subsume a wide spectrum of visually distinct behaviors (generic coding; e.g., walk, gesticulate, etc.). Second, coding is often restricted to behaviors that are well defined and unmistakable (restrictive coding; e.g., turning head toward or away from someone). Third, observational rating methods are used to interpret nonverbal behavior. Not only are behaviors described in generic or restrictive terms (e.g., inhibited, agitated); they are also supposed to be translated into psychological dimensions, although no guidelines are provided on how to do so. In this respect, the procedures that can be used to transcribe the nonverbal behavior range from identifying distinguishable elements of behavior to judging the presumed effects of behavioral elements. For that purpose, the observers, as the external experts on recognizing nonverbal behavior, can include diverse elements of nonverbal behavior, depending on their capacity for decoding.

However, the observers' ability to code behavior accurately is limited if, for example, the labels provided do not describe specific behaviors clearly, the alternative categories used are almost alike, individual categories overlap, or behavioral sequences are complex and rapid. Interpretations can be improved by training the observers to use exactly defined coding strategies with evidence of interrater reliability. But reliability does not ensure validity. It should not be overlooked that the elements that are necessary to identify a movement pattern must be operationalized before instructions on classification can be given. This can be illustrated with regard to head movements - for example, turning one's head toward a person one is conversing with-which are understood as complex patterns of interaction made up of various components. Therefore, an analysis of head movements can be undertaken at various levels: (1) It can depict a head movement as a set of consecutive muscle contractions; (2) it can distinguish between sagittal and lateral components of movement, depending on the degrees of freedom of head movements; (3) it can focus exclusively on temporal or on qualitative aspects (frequency or size); or (4) it can mark attention-giving behavior. Obviously, no clearcut decision can be made as to whether parameters are critical for a particular movement pattern and which ones are necessary for a differentiation between movement patterns. Therefore, the investigators must be aware of the fact that, by choosing a method for rating body movements, they have also implicitly defined the phenomenon nonverbal behavior. Thus, attempts to measure complex behavior with more or less restrictive behavioral rules call for knowledge of relevant behavioral elements. Moreover, retaining only predefined or familiar manifestations and units of behavioral components makes it impossible, for example, to discover behavioral patterns that had hitherto been inaccessible to the viewers' conscious reflection. As a result, there has been a call for new methods of measurement that ensure accurate behavioral transcriptions, on the one hand, and exploration of the complexity of movement patterns, on the other.

Descriptive transcriptions. In an attempt to remedy previous methodological shortcomings, Frey et al. (1981) developed a coding system that attempted to transcribe behavior as precisely as possible (see Frey et al., 1981; Hirsbrunner, Florin, \& Frey, 1981; Hirsbrunner, Frey, \& Crawford, 1987). Classification is based on a spatiotemporal transcription of various parts of the body, including the head, trunk, shoulders, upper arms, upper thighs, and feet. Two or more dimensions of movement are video indexed once every half second. The method provides a transcription of movement activity (e.g., 125 different head positions can be distinguished for each time of measurement), and a time-series notation of coded video frames makes it possible to elaborate a data protocol that reconstructs the subjects' original positioning very accurately $(98 \%)$. However, a coding scheme as complex and time consuming as the one devised by Frey et al. would not be a feasible method of analyzing movement behavior in longer conversations. In addition, the suggestions for assessing the data protocols elaborated by Frey et al. do not question the concept of behavioral transcription per se but, rather, underline the limitations of hand coding in general. Therefore, indirect methods of measuring nonverbal behavior are bound to reduce behavior even if very elaborate strategies for behavioral transcription are employed. This is generally due to the fact that the categories used are based on ordinal or even only on nominal data. However, portraying complex behavior-such as that displayed in human face-to-face interaction-calls for the possibility of transforming the quantified raw data back into visible behavior. This requires that the raw data contain as high a level of data as possible (interval scale), so that the phenomenon of the behavioral continuum can be accounted for by a method with optimal temporal resolution and the possibility of extrapolation. Even refined methods developed to date have failed to meet these requirements. Therefore, the behavior observed is precategorized and classified according to impression (by using rating scales), frequency (by counting specific categories), or size (by using ordinal categorization). Thus, the focus of research attention is less on visible behavior than on the systematic occurrence of specific categories, which, in turn, cannot be changed or examined.

\section{Requirements to be Met by Direct Methods of Measurement}

Depending on their resolution power (number of dimensions and time plot used), direct methods of measurement can record a great body of data that serves as the physical basis for subsequent steps in the analysis process. In this respect, direct methods have to define algorithms that transpose raw data into movement patterns. The reliability and validity of the unit and of further mathematical procedures can be determined most easily using model movements - for example, a pendulum or a 
computer-driven head model (see Jossen, 1996; Tyron, 1991). As physical measurements and their conversion into movement patterns cannot include functional classification per se, both methods of quantifying movement patterns and methods of determining the relationship between body movements and their functions in a given context have to be developed. Such methods have to give special attention to the situation in which movement behavior takes place. Functions of a particular behaviorwhich are primarily shaped by the way one's partner appraises the situation - can only be inferred by including the social context in which an interaction occurs (see Altorfer, 1988). In other words, direct methods of measuring nonverbal behavior call for the following three interrelated steps, which replace the coding process used in indirect methods. First, a collection of physical raw data should be done, for which accuracy of measurement depends on the power of resolution of the measurement device. Second, an extraction of movement units and movement patterns has to be implemented. The sensitivity of these procedures should be adjusted by varying constants in conversion. Third, an elaboration of an empirical frame of reference should be used, which ensures the examination of the functional effects of movement.

\section{MEASUREMENT OF HEAD MOVEMENTS}

To remedy the criticisms noted above, any new measure of head movement activity has to meet the following requirements.

1. It has to be able to transcribe physical measures of head movements into plausible characteristics of movement that depict behavioral manifestations in isomorphic terms.

2. Besides measuring ongoing head movements, it has to be able to divide movements into segments (movement units) that validly reflect visible behaviors. In this respect, establishing the validity of head movement detection (as opposed to the reliability for coding procedures) is done by making decisions as to the sensibility of mathematical transformations and algorithms.

3. In addition, possibilities of forming head movement patterns should be elaborated that can ensure a valid empirical approach to the problem of categorization of different behaviors.

4. It should be possible to establish a relationship between the data protocols of nonverbal behavior and context variables at each individual step of analysis (ranging from raw data collection to movement patterns). A comprehensive analysis of social situations and verbal interaction must accompany the analysis of head movements. In this respect, methodological links to other behavioral domains should provide additional procedures that evaluate, for example, the course of verbal interaction (see Käsermann, Altorfer, Foppa, Jossen, \& Zimmermann, 2000) and variables of psychophysiological activity (see Jossen et al., 2000).

\section{Method \\ Raw Data Collection \\ A system (V-Scope VS-110 PRO; Eshed Robotec, Inc.,} $\left.1990^{\prime}\right)$ that measures the coordinates $(x, y$, and $z)$ of small ultrasonic transducers in space is used to record data. It involves attaching transducers the size of a button ( 26 $\times 26 \times 17 \mathrm{~mm}^{3}$ ) to the index person's body. These transducers are activated separately with an infrared signal, and they then send ultrasound signals to three ultrasound receivers that are mounted on the ceiling. The position of each transducer in space is calculated by a central unit (V-Scope microcomputer) on the basis of distances between transducers and receivers and transformations of these distances to $x, y$, and $z$ projections in a Cartesian coordinate system (triangulation). These positions are noted with a time stamp and are transmitted from the V-Scope microcomputer to the host computer (IBMcompatible $\mathrm{PC}$ ) through connection at the serial port (RS232C-interface).

The device presently available is designed for eight transducers. The transducers are always called up in the same order, whereby the same transducer sends positions every 40 or $80 \mathrm{msec}$, depending on the system's sampling rate ( 200 or $100 \mathrm{samples} / \mathrm{sec})$. This cyclical query requires the placement of transducers so that corresponding anatomical structures follow each other as quickly as possible (e.g., head right and head left or shoulder right and shoulder left). Figure 1A shows where they are attached to the index person's body. Either all eight transducers can be used with one index person (to record the entire upper part of the body; see Altorfer, Jossen, \& Würmle, 1997) or four transducers can be used with two index persons each (to record head movements).

The recording system detects transducers' movements that are smaller than $0.5 \mathrm{~mm}$. With the help of a test program, background noises in the ultrasonic domain, ultrasonic echoes, and changes in temperature and in draft can be measured. Even if disturbances cannot be eliminated manually, reception can be optimized by using, for example, variable sensitivity of the receivers and digital filters. Recording the coordinates of eight transducers (raw data) in space has two disadvantages that necessarily detract from the accuracy of direct behavioral transcription. (1) The index person is hindered to a certain yet reportedly negligible extent by a system that involves having to attach transducers to the index person's body. (2) Since transducers must have line-of-sight contact with decoders, they can transmit or receive signals within an angle of $160^{\circ}$. Therefore, they might fail to transmit certain movements, but this can be compensated for, to some extent, by extrapolation between the last coordinates before failure to record and the first coordinates after failure to record.

\section{Data Evaluation}

After having recorded the raw data, six consecutive steps are undertaken to analyze them. 


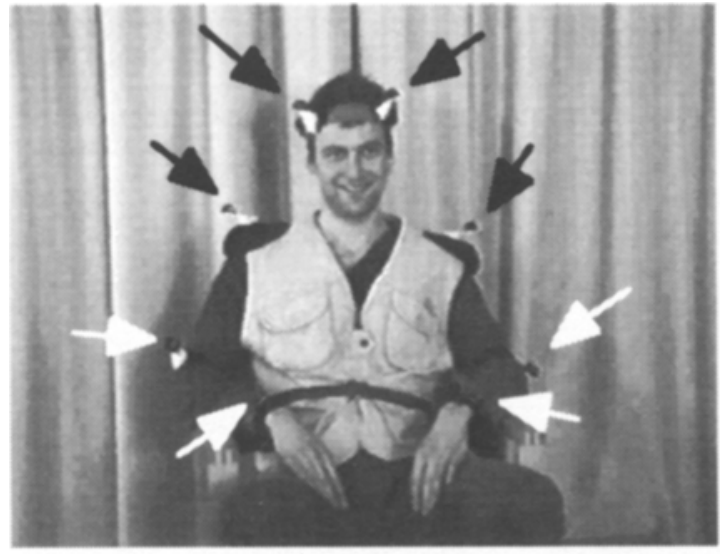

A

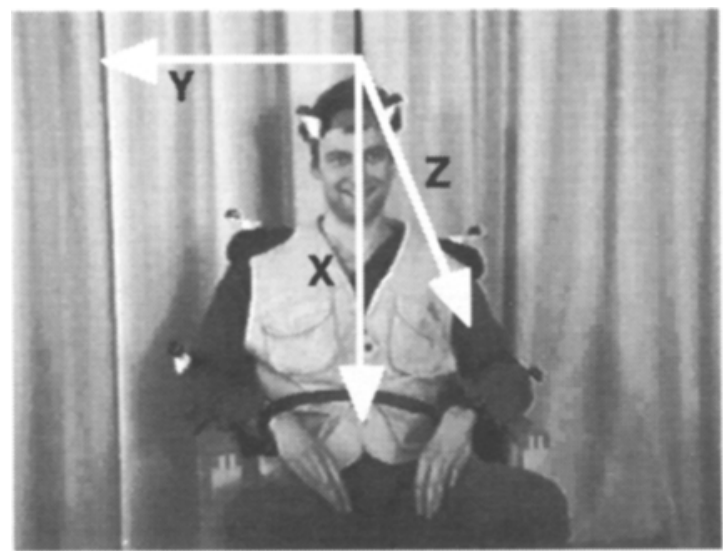

B

Figure 1. (A) Positions of eight ultrasonic senders (head movements: head right, head left, shoulder right, shoulder left; arm movements: elbow right, elbow left, wrist right, and wrist left). (B) Cartesian coordinate system: $x$, vertical axis; $y$, horizontal axis parallel to the straight line between shoulder transducers; and $z$, horizontal axis parallel to the person's line of vision.

Step 1. The positions of the head are computed on the basis of the time-series of the separate transducers.

Step 2. Relevant changes are identified in certain dimensions of head movements.

Step 3. Possibilities of defining and extracting movement units are pinpointed.

Step 4. Head movement patterns are quantified and categorized.

Step 5. The situational context in which movement behavior takes places is assessed by using a time-matched method of recording various behavioral channels.

Step 6. A conceptual (research-related) relationship between rules of proceeding that have hitherto been ex- clusively behavioral ones and the situational context has to be elaborated.

The examples presented throughout the technical presentation (Figures 2-4 and Table 1) always refer to the same, approximately 10 -sec segment of the series of raw data collected

Step 1: Determining positions of the head. The first step of analysis involves transcribing the coordinates of transducers into head positions (Böhlen \& Liechti, 1992). In keeping with the situation in which data are collected, the index person is in a Cartesian coordinate system consisting of the $x, y$, and $z$ projections. When the three receivers are attached to the ceiling, the $z$-axis refers to the

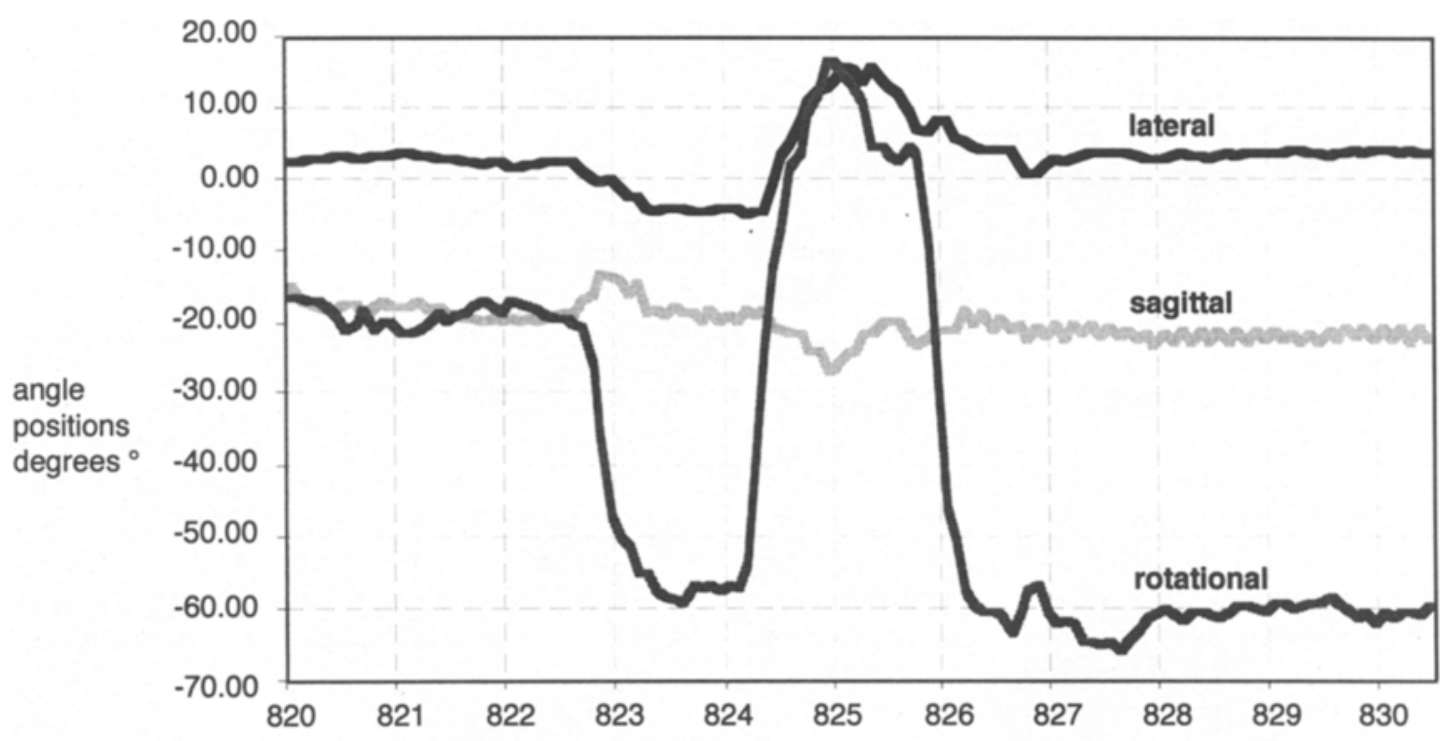

Time (s)

Figure 2. Head movements given as angle positions in three dimensions: lateral $(x, y$ coordinates $)$, sagittal $(x, z$ coordinates), and rotational ( $y, z$ coordinates). 
test person's line of vision. The $y$-axis describes the horizontal axis parallel to the straight line which is defined by both transducers attached to the shoulders, and the $x$ axis describes the vertical axis (see Figure 1B). Angle positions are thus calculated for head movements (with reference to anatomical features of the subject) in terms of lateral, sagittal, and rotational dimensions on the basis of the raw data protocols (Figure 2). The positions that can be distinguished within a particular dimension are defined as displacements, or flexions, from a standard upright head position. A constant vector for the forehead is defined so that shift in head positions can serve as a direct measure of the intensity of head movements $(\% / \mathrm{sec})$. Angle positions are tested concerning their presentational possibilities. In this respect, "biologically improbable events" are excluded by defining critical ranges of angle positions in each dimension (equations and diagrams are printed in Altorfer, Jossen, \& Würmle, 1997). ${ }^{2}$

Step 2: Relevant changes. The angle positions for the lateral, sagittal, and rotational head positions are the starting point for extracting relevant changes of head movements. In a first step, the data series of angle positions is reduced to information about the local gradient with the help of the differences between two adjacent values. Next, relevant changes are identified by using an averaged mean of three points. At a recording rate of $80 \mathrm{msec}$, this corresponds to a window of $240 \mathrm{msec}$, which is used throughout the entire data string. Criteria are defined for each separate dimension (lateral, sagittal, and rotational) and convey information about the following points: the minimal duration of a change ( $D M o v \geq 0.24 \mathrm{sec}$ ), the minimal duration of a pause (DPause $\geq 0.24 \mathrm{sec}$ ), the minimal distance between events $(D D \geq 0.24 \mathrm{sec})$, the critical speed of a change (VMov $\geq 8.4 \%$ sec, which means that the sum of three adjacent difference values should be $\geq 2^{\circ}$ ), and the critical speed of a pause (VPause $\leq 8.4^{\circ} / \mathrm{sec}$, which means that the sum of three adjacent difference values should be $\leq 2^{\circ}$ ). These criteria can be determined for each individual subject on the basis of the distribution characteristics of the separate data strings. In addition, the criteria used to quantify relevant changes and pauses can be adjusted on the basis of the requirements of research questions of interest. For instance, great shifts in position could be differentiated from phases of extreme immobility by increasing the critical speed of change ( $V M o v \geq 20^{\circ} / \mathrm{sec}$ ) and decreasing the critical speed of a pause (VPause $\leq 4^{\circ} / \mathrm{sec}$ ). In an effort to exclude velocities of movements that go beyond the limits of biological possibilities, a critical speed for artifacts (VArtifact $\geq$ $200 \% \mathrm{sec}$ ) is defined. If a dimension exceeds this speed limit, it is not evaluated. The criteria mentioned are applied to each data dimension (lateral, rotational, and sagittal), which enables deciding whether a change in speed is critical on the basis of the following logic: A data channel is in movement (or at rest) at time $T_{j}$ if the change in speed $V M(V P)$ at this point in the data series is larger (smaller) than the critical speed of change $V M O v$ (VPause) that has been defined for this dimension (see Equations 1 and 2). The difference between the last and the first data points of a dimension (divided for the positive or the negative direction) that fulfill these criteria thus yields the magnitude of relevant movement. The same method can be used to determine pauses in relationship either to distinct dimensions or to combinations of dimensions. Therefore, no movement is equivalent to a pause in all three dimensions. Thus, with the help of this procedure, a data sheet containing all the relevant events can be compiled (Table 1). Passages that do not meet any of these criteria are regarded as noise. They are identified on the basis of the difference between the beginning of the event and the end of the previous one (the "No Critical Event" column in Table 1).

Step 3: Movement units. In order to be able to distinguish movements from one another and to code them as behavioral manifestations, it is necessary to identify the boundaries that separate movement patterns. There are more or less large intervals between the relevant changes in head movements - noted in terms of the three dimensions used (lateral, sagittal, and rotational) - which were computed in Step 2. Since no movement and relevant changes are disjunctive events, all the relevant shifts in head movements that occur between two phases in which no movement takes place are classified as belonging to the same movement pattern. In addition, boundaries can also be defined by providing information about the critical duration of phases between two relevant changes (in the example depicted in Table 1 and Figure 3, critical duration $\geq 0.5 \mathrm{sec}$ ). In Figure 3, two head movements are shown differentiated by means of this procedure. Frames 2-4 depict a movement that is characterized by predominant rotational elements and by weaker sagittal ones. Frames 7-16 show a head movement that involves all three dimensions, particularly rotational shifts. In addition, this movement is quantified as a back and forth movement, since no pause takes place between the changes in direction of the rotational movement that meets the criteria selected (Frame 11).

Step 4: Quantifying movement patterns and possibilities for categorization. In order to quantify head movement patterns, separate movements-which are com-

$$
\begin{aligned}
& \left(\text { Status }\left\{\begin{array}{l}
\text { lat } \\
\text { sag } \\
\text { rot }
\end{array}\right\}\left[T_{j}\right]=\text { Movement }\right) \Leftarrow\left(V M\left\{\begin{array}{l}
\text { lat } \\
\text { sag } \\
\text { rot }
\end{array}\right\}\left[T_{j}\right]\right)>V M o v\left\{\begin{array}{l}
\text { lat } \\
\text { sag } \\
\text { rot }
\end{array}\right\} \\
& \left(\text { Status }\left\{\begin{array}{l}
\text { lat } \\
\text { sag } \\
\text { rot }
\end{array}\right\}\left[T_{j}\right]=\text { Rest }\right) \Leftarrow\left(V P\left\{\begin{array}{l}
\text { lat } \\
\text { sag } \\
\text { rot }
\end{array}\right\}\left[T_{j}\right]\right)<\text { VPause }\left\{\begin{array}{l}
\text { lat } \\
\text { sag } \\
\text { rot }
\end{array}\right\} \text {. }
\end{aligned}
$$


Table 1

Sample of Data Sheet Indicating Relevant Changes and Durations Without Critical Events, Which Succeed Them

\begin{tabular}{|c|c|c|c|c|c|c|c|}
\hline Start (sec) & End (sec) & Duration (sec) & $\begin{array}{l}\text { Position } \\
\text { at Start }\left({ }^{o}\right)\end{array}$ & Integral & Movement $\left({ }^{\circ}\right)$ & Dimension & $\begin{array}{c}\text { No Critical Event, } \\
\text { Duration (sec) }\end{array}$ \\
\hline 820.27 & 820.51 & 0.24 & -16.72 & 0.63 & -4.32 & rotational & 0.24 \\
\hline 820.75 & 820.91 & 0.16 & & & & no movement & 0.08 \\
\hline 820.99 & 821.07 & 0.08 & & & & no movement & 0.08 \\
\hline 821.15 & 821.71 & 0.56 & -20.94 & 1.09 & 4.07 & rotational & 0 \\
\hline 821.71 & 822.35 & 0.64 & & & & no movement & 0 \\
\hline 822.35 & 823.39 & 1.04 & -19.45 & 18.39 & -39.48 & rotational & 0 \\
\hline 822.51 & 822.75 & 0.24 & -19.14 & 0.66 & 5.89 & sagittal & 0 \\
\hline 822.51 & 823.15 & 0.64 & 2.49 & 2.20 & -6.64 & lateral & 0 \\
\hline 822.83 & 823.47 & 0.64 & -13.33 & 1.36 & -5.50 & sagittal & 0 \\
\hline 823.47 & 823.71 & 0.24 & -59.15 & 0.48 & 2.57 & rotational & 0.24 \\
\hline 823.95 & 824.75 & 0.80 & -56.82 & 35.24 & 73.46 & rotational & 0 \\
\hline 824.19 & 824.91 & 0.72 & -4.61 & 9.02 & 20.18 & lateral & 0 \\
\hline 824.51 & 824.75 & 0.24 & -21.77 & 0.64 & -4.99 & sagittal & 0.08 \\
\hline 824.83 & 825.23 & 0.40 & -26.55 & 1.42 & 6.60 & sagittal & 0 \\
\hline 824.83 & 825.39 & 0.56 & 16.68 & 3.51 & -14.30 & rotational & 0 \\
\hline 825.15 & 825.87 & 0.72 & 15.63 & 2.92 & -9.89 & lateral & 0 \\
\hline 825.47 & 826.35 & 0.88 & 4.73 & 18.94 & -67.93 & rotational & 0 \\
\hline 826.35 & 826.59 & 0.24 & -63.20 & 0.96 & 6.54 & rotational & 0.32 \\
\hline 826.91 & 827.31 & 0.40 & -61.92 & 0.49 & -3.63 & rotational & 0 \\
\hline 827.31 & 827.71 & 0.40 & -65.55 & 1.26 & 5.42 & rotational & 1.44 \\
\hline 829.15 & 829.39 & 0.24 & -58.62 & 0.31 & -2.43 & rotational & 3.28 \\
\hline 832.67 & 833.87 & 1.20 & -60.68 & 7.30 & -13.66 & rotational & 0 \\
\hline 832.75 & 833.63 & 0.88 & 4.67 & 2.82 & 6.27 & lateral & 1.52 \\
\hline 835.15 & 835.39 & 0.24 & -73.31 & 0.54 & 4.63 & rotational & 0.08 \\
\hline 835.47 & 835.71 & 0.24 & -68.92 & 0.38 & -2.88 & rotational & 0.80 \\
\hline
\end{tabular}

Note--The period from 823.95 to 826.59 represents a single period of movement, corresponding to the head movement pattern shown in Figure 2, Frames 7-16 of Figure 3, and the graphic representation in Figure 4.

bined into units of movements in accordance with the criteria mentioned above-have to undergo evaluation. The following parameters play a central role in the quantification of head movements: the relative predominance of each dimension, the onset of each dimension (its place in the course of the movement pattern), and its duration. Each head position is a vector point that depicts ongoing movements within a time perspective (unit is equivalent to the rate of recording movement-e.g., $80 \mathrm{msec}$ ). This series of vector points is represented in graphs (pattern graphs, with vectors as hypotenuses; triangles correspond to integral) for the three head dimensions (lateral, sagittal, and rotational) with the corresponding time information (see Figure 4). This method of illustrating head movements may seem rather complicated at first glance. However, by plotting each separate head dimension and combinations of all the dimensions as well, an accurate visualization of complex movement patterns is obtained. Therefore, it is easy to inspect prominent shifts in head position without neglecting slight changes, in particular in the lateral and the sagittal areas.

Movement patterns are grouped, using a method known as template matching (Haralick \& Shapiro, 1992, 1993), which takes into account the fact that movement patterns are not necessarily of equal duration. In order to determine the similarity between two movement patterns, the graph with the shorter duration is "pulled over" the graph with the longer duration. For two movement patterns A and $\mathrm{B}$, this means, for example, that the correlation be- tween each point of vector $A$ and the corresponding poin1 of vector $B$ is computed. The sum of the correlations for vector A yields a measure of agreement at time $t_{0}$. This sum is computed at time $t_{1}$ to $t_{x}(x=$ number of time segments). Thus, similarity is defined in terms of spatial coordinates, on the one hand, and its timing, on the other. What can be stored as data is either the greatest similarity throughout the entire movement pattern or the mean level of agreement obtained. Individual classes and groups can be formed, depending on the question to be addressed by research. In order to illustrate how this procedure works, a group of movements will be described that greatly resemble one another on the rotational dimension. To simplify matters, description will be limited to one dimension of movement (in this case, the rotational one). In the first comparison, a common starting time is chosen (see Figure 5A). In this example, the correlation for the common sector between Movement Pattern A and Movement Pattern B is $r=.677$. In the second comparison, the shorter movement pattern is moved along for one unit (see Figure 5B). In the example presented, the correlation between the time that is common to both Movement Pattern A and Movement Pattern B is $r=1.0$. In the third and last comparison carried out, the onset of the shorter movement pattern corresponds to the difference of the duration of Movement Pattern B minus the duration of Movement Pattern A (see Figure 5C). The correlation for the period that Movement Pattern A and Movement Pattern $\mathrm{B}$ have in common is $r=.696$. On the average, there 


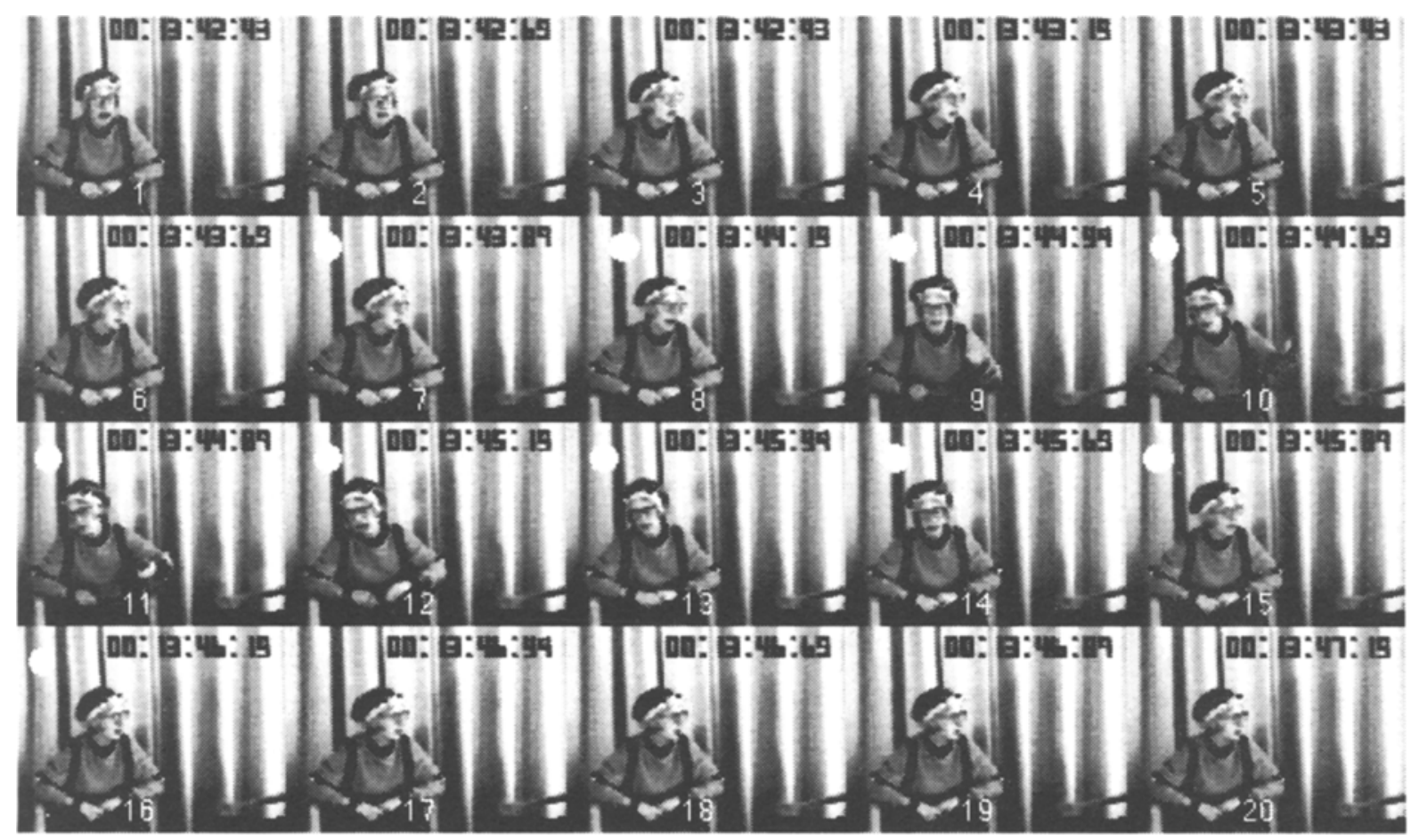

Figure 3. Stills of video recording of head movements (Frames 2-4, 7-16) and arm movements (Frames 8-12).

is a fair amount of agreement $(r=.791)$ in the rotational dimension, whereby there is complete agreement $(r=1.0)$ in the sequence of both movements at time $t_{1}$.

With the help of the procedure outlined in this section, quantitative features (similarity measures) that can be used to classify movement patterns can be computed. In accordance with the principles of unsupervised learning (Quinlan, 1991), it is possible to group movement patterns on the basis of calculated similarity measures that are compared with critical values for desired similarities (e.g., threshold similarity correlation $S 0>.8$; see Figure 6). The critical value for similarity should be conservative for homogeneity's sake-that is, it should be as high as possible (e.g., correlations ranging between .8 and 1.0 ; see Duda \& Hart, 1973). ${ }^{3}$

Step 5: Integrating data obtained in behavior analysis with other variables (verbal activity, psychophysiology). An integral part of the procedure for measuring and analyzing head movement behavior described in this paper is the synchronization of various channels of behavior. This approach has also been adapted in various other applications (see Altorfer, Goldstein, Miklowitz, \& Nuechterlein, 1992; Käsermann \& Altorfer, 1989, 1990, 1994). The use of a common time code enables recording nonverbal data, the course of verbal interaction, and physiological activity (finger pulse volume, electrodermal activity, etc.), all at the same time (see Altorfer, Hirsbrunner, \& Käsermann, 1990; Altorfer, Käsermann, \& Hirsbrunner, 1991; Käsermann et al., 2000). In addition, verbal interaction can be sequenced with the help of var- ious programs that ensure the identification of on-off characteristics, on the one hand, and a very accurate transcription of specific event protocols, on the other (see Käsermann et al., 2000). Behavior analyses that incorporate various data channels in this manner were conducted in particular in studies concerned with the relationship between verbal stressors and physiological stress reactions in conversation (Altorfer et al., 1992; Altorfer, Käsermann, \& Hirsbrunner, 1998; Käsermann \& Altorfer, 1989, 1990, 1994; Käsermann, Altorfer, \& Hirsbrunner, 1998).

Step 6: The concept of a relationship between nonverbal analyses and situational context (research strategy proposed). The method for analyzing nonverbal behavior described in the previous sections of this article proceeds from first objectively quantifying and classifying movement activity (Steps $1-5$ ) to then examining its psychological significance by interpreting it within the social situation in which it was evidenced. Attention should be given to the following two problem areas that play an important role in the analysis of movement behavior.

The first problem involves an individual's nonverbal behavior that is independent of the setting in which communication takes place. For example, an individual's head movements may be due to organic disorders, such as extrapyramidal-motor symptoms that are adverse reactions to neuroleptic medication (see Kane, Schooler, Marder, Simpson, \& Casey, 1994). Beyond that, an individual's head movements (in the sense of motor disorders) may be produced by all kinds of positive or negative emotionalizations or by serious central nervous dysfunctions (see 

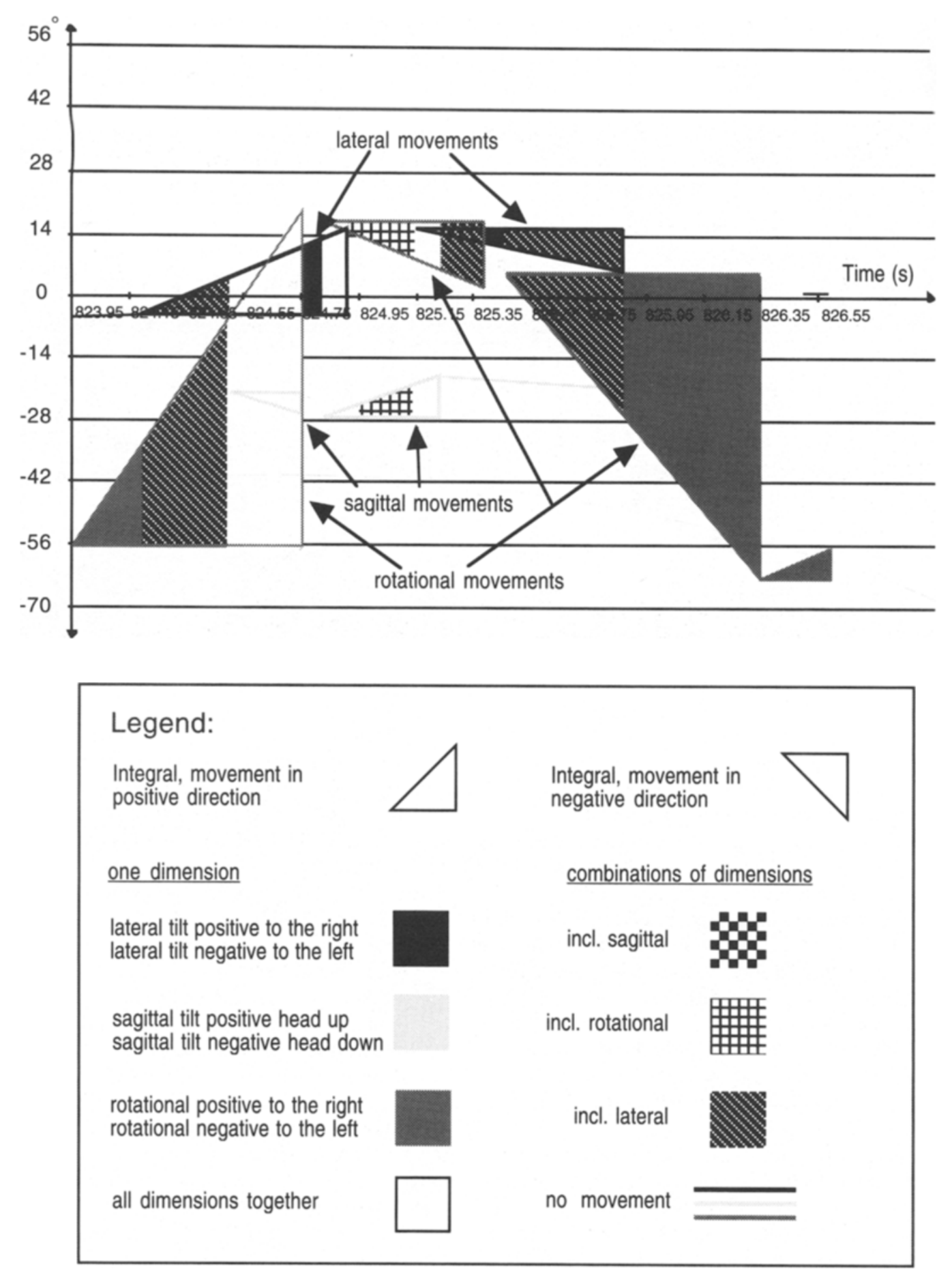

Figure 4. Head movement pattern of Frames $7-16$ in Figure 3 and of boldface data in Table $1(x$-axis $=$ time in seconds, $y$-axis = head positions in degrees) given as a pattern graph of three dimensions, with triangles (integrals) and vectors as hypotenuses.

Parsons \& Nixon, 1993). Thus, some behavioral manifestations may be explained exclusively by the individual's biological state at the given time, rather than by a social situation. Therefore, an analysis of movement patterns should encompass an individual perspective in which personal factors are investigated as much as possible.
The second problem is that movements may assume an interactional meaning as soon as the person with whom one is interacting interprets them. This context defines the second area concerning social situations, in which movement behavior accompanies communication. The exchange of verbal information thus constitutes the cen- 
A

Match $t_{0}$

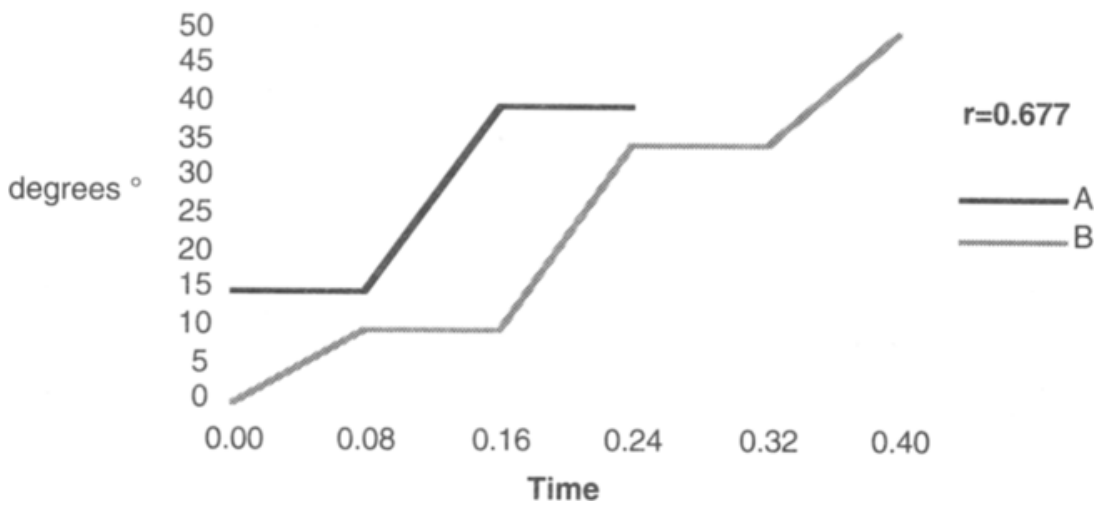

B

\section{Match $\mathrm{t}_{1}$}

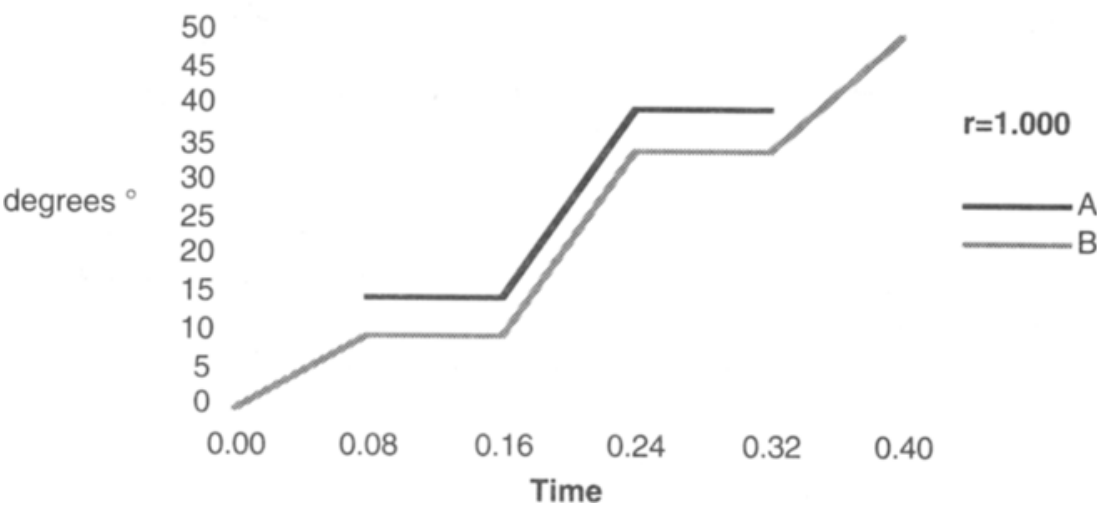

C

Match $\mathbf{t}_{\mathbf{x}}$

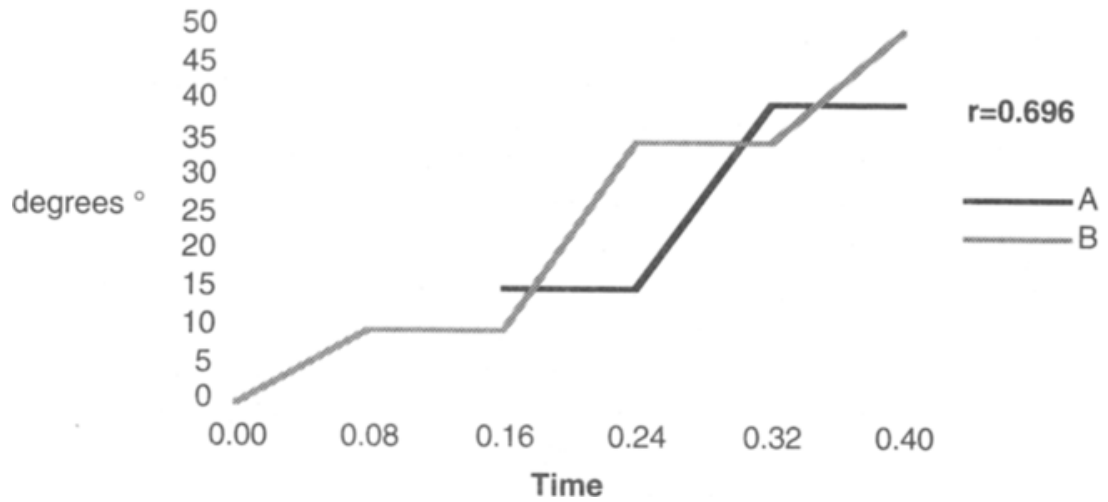

Figure 5. A template-matching example of two rotational movement patterns, $A$ and $B$ (head rotations in positive direction).

tral structure (e.g., dividing conversation into separate contributions) in which nonverbal behavior is embedded. It supplements other channels and serves various specific functions (see, e.g., semantic, syntactic, pragmatic, and dialogic functions, as outlined by Scherer \& Wallbott,
1985). As is illustrated in the first five steps of the method for analyzing head movement behavior, analyses that rely on direct methods do not per se contain information about either the interactional meaning of behavioral patterns or the function they are intended to serve. Thus, it 


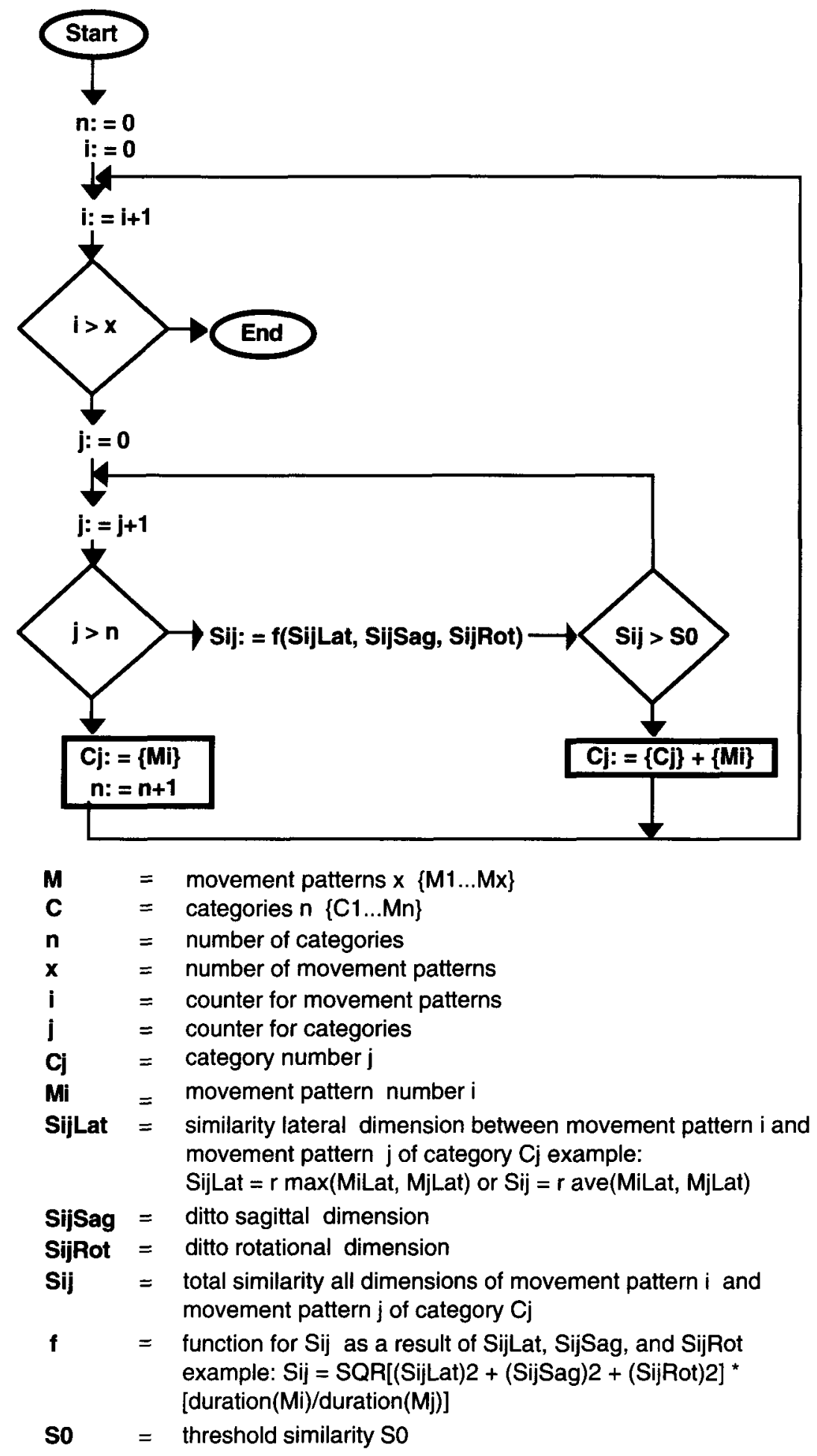

Figure 6. Categorization of head movement patterns by using template matching and similarity measures.

is imperative that movement analyses must be grounded in a research concept that allows attributing interactional meaning (as an interpretable sign) to categories of movement patterns in an empirical manner. This concept is based on the notion that the minimal unit of interpreta- tion in communication can be depicted as a sequence of three functionally related contributions of Speakers A and B (A1-B1-A2; see Käsermann, 1983, 1995; Käsermann et al., 2000). The speaker in the A-position can evaluate B's interpretations of Al by using a corrective 
rejection of B's understanding in A2. This unit can be adapted to interpret head movement patterns as follows. In a permutable analysis window consisting of three consecutive statements, classes of equivalence (Al-B1) are formed that are subsumed, for example, as adjacency pairs, such as question-answer or statement-comment (Sacks, Schegloff, \& Jefferson, 1974; Schegloff \& Sacks, 1973). Concomitant movement patterns are regarded as independent variables in terms of these adjacency pairs and are examined as to their possible effect on the subsequent course of interaction. If there are any systematic relationships between head movement patterns engaged in while a subject is talking (B1) and the verbal behavior subsequently engaged in by an interactional partner (A2), embedding nonverbal behavior in its context suggests meaningful interpretations.

This research strategy can be illustrated by using an established iconic head movement pattern. For example, the meaning of a movement pattern that is characterized by sagittal shifts in position in a positive and a negative direction (lifting and lowering) can be recognized by using the analytical procedure outlined above. The head movement pattern in question may be regarded as iconic gesture head nodding, which can enhance or even replace the verbal communication of affirmation if the following assumptions are correct. Constant adjacency pairs (question-answers) are either accompanied by verbal remarks ("yes," "yes, exactly," etc.) or followed by subsequent reaction of the partner (A2), which indicates that the subject's preceding utterance is understood as an affirmative answer (Bl) to the question asked (Al). Therefore, the relationship between categories of head movement patterns and verbal exchange is crucial for an attribution of meaning. Consequently, with the help of this heuristic, a catalogue of interpretations can be elaborated by considering all variables that give evidence for the meaningful aspects of nonverbal behavior (verbal course, psychophysiology, situational features, etc.). In the present example, the head movement pattern in question is related either to affirmative verbal comments of Subject B in BI ("yes," "yes, exactly," etc.) or to an affirmative interpretation of Subject B's behavior in Bl by the partner, $\mathrm{A}$, in $\mathrm{A} 2$.

Concerning movement patterns without verbal concomitants, the most important indications of functional nonverbal acts are found in the partner's interpretation of a subject's behavioral moves. In this case, no evidence for meaningful head movement patterns can be found in Subject B's behavior itself. Therefore, the partner's comprehension serves as criterion for the detection of meaningful head movement activity. On the basis of the verbal part of communication, interactive situations ask for an explication concerning their communicative correctness. This means, from the partner's viewpoint, situations with inconsistent or incomplete verbal exchange-for example, an incorrect or unsatisfactory answer of Subject $\mathrm{B}$ in $\mathrm{B} 1$-require a request for amplification unless other evidence is drawn, for example, from nonverbal be- havior. In this latter case, occurring head movement behavior may be regarded as a substantial communicative sign that extends pure verbal interaction. In this respect, relations between head movement patterns and a partner's interpretations of a subject's communicative moves are regarded as indices for meaningful behavioral acts that influence conversational behavior like "words" in language. Therefore, head movement patterns that take place in a social context are tested concerning their power to enhance aspects of verbal communication that contain incomplete information for understanding an interactive exchange. This research strategy is especially suited for the recognition and analysis of potential communicative characteristics of nonverbal behaviors that have been unknown up to now.

\section{AREAS OF APPLICATION}

The system for recording and analyzing head movement behavior presented so far can be used in various areas. As was depicted in Step 6 of the analysis, areas of application can be roughly divided into two groups: those that tend to focus more on individual aspects of behavior as an expression of a psychic or biological state versus those that focus more strongly on the social aspects of behavior as an integral part of the communication process.

\section{Head Movements as a Diagnostic Tool}

In diagnosis, movement behavior is usually focused on as a symptom of an organic or a mental disorder. This applies to movement measurement (e.g., intensity of head movement, head rotations in one or in several dimensions, etc.), which is performed in differential diagnosis (tremor, motor disorders, etc.) or in psychopharmacological research (evaluation of effectiveness, specific side effects, etc.). For example, reduced head movements point to serious deficits in motor activity in schizophrenic patients undergoing neuroleptic treatment (Altorfer, Jossen, \& Würmle, 1996; Altorfer, Merlo, \& Jossen, 1997; Altorfer, Merlo, Käsermann, Jossen, \& Hofer, 1998). Usually, rating scales are used to assess drug-induced motor side effects within extrapyramidal syndromes (EPS)-for example, drug-induced parkinsonism, with particular emphasis on symptoms of rigidity, acute dystonia, akathisia, and akinesia (see, e.g., the Neurological Rating Scale; Simpson \& Angus, 1970). As a substitute for these rating scales, the quantification of head movements offers new ways of analyzing the symptoms of EPS and their influence in an interactive context. In Altorfer (1999), head movement patterns were analyzed with respect to concerning some selected aspects. First, a score of movement velocity was calculated for each movement pattern. Second, the head movement patterns were categorized according to their quantitative and qualitative complexity. In this respect, a categorization was done that classified minimal head movements with changes of less than $5^{\circ}$ in the rotational dimension and/or less than $2.5^{\circ}$ in the lateral and/or sagittal dimensions, as well as substan- 
tially bigger head movement patterns that included one, two, or three dimensions (i.e., combined movement patterns). These behavioral variables were measured during a 10-min interaction task in which an interviewer tried to maintain a conversation about actual daily activities. From this procedure, some data of a Phase IV (postapproval) drug trial were reported, which involved firstepisode schizophrenic patients (diagnosed according to DSM-IV criteria; American Psychiatric Association, 1994) and unmedicated normal controls. The investigation evaluated two different doses ( 2 vs. $4 \mathrm{mg}$ ) of Risperidone (i.e., a neuroleptic drug with potentially reduced adverse effects) in a double blind design after 28 and 56 days of treatment. Compared with normal controls $(n=12)$, the patients' movement velocity in head movement patterns significantly decreased [Day 28, $t$ test, 31 patients: $t(d f=41)=8.173, p<.0001$; Day $56, t$ test, 28 patients: $t(d f=38)=7.322, p<.0001$ ]. Moreover, they displayed a serious deficit in movement behavior, with a predominance of minimal movements and only a few combined movement patterns, as compared with normal controls [Day 28, two-way analysis of variance (ANOVA), 31 patients: $F(3,164)=43.772, p<.0001$; Day 56, two-way ANOVA, 28 patients: $F(3,152)=$ $34.787, p<.0001]$. Follow-up data collection at 6 and 12 months in an open design (i.e., 8 and 14 months of neuroleptic treatment) that followed the double blind phase revealed different effects, depending on the neuroleptic treatment strategy used. Longitudinal comparisons within patients showed, on the one hand, correlations between dose of medication (measured in plasma levels) and the quality of head movement patterns (e.g., higher dose, increase of minimal head movements). On the other hand, a significant normalization of head movement behavior was discovered with patients who changed neuroleptic medication to Clozapine [two-way ANOVA, with 28 and 56 days of treatment and 6 and 12 months follow up as repeated measures, 9 patients: $F(9,96)=9.641, p<.0001$ (Greenhouse-Geisser $\mathrm{E}=$ $0.56, p<.0001$ ); see Altorfer, 1999].

The quantification of head movement patterns proved to be a very sensitive instrument that reflected dose- and medication-dependent changes of EPS. Besides these individual aspects, diagnostic features (as clinical signs of EPS) are relevant as well with respect to social situations. It is evident that the reported poor head movement activity resulted in reduced possibilities to receive and, especially, to send nonverbal signs in communication. Undermining psychotherapeutic aims, such motor disorders may negatively influence the patients' social responsiveness to partners, as well as impression formation in partners (Altorfer, 1999).

\section{Head Movements in Dyadic Interaction}

By embedding behavioral assessment in its context, analysis can focus on the various communicative aspects of head movement behavior. Questions about the interactive functions of head movement behavior can be clarified by means of the step-by-step procedure for movement analysis presented earlier in this paper. The procedures allow a thorough assessment of the context in which movement behavior takes place by using both additional behavioral data (e.g., psychophysiological measurement, Step 5 of the analysis) and communicative information of the situation (Step 6 of the analysis). Continuous speech in conversation is normally accompanied by head movements that are important for the understanding of communication. However, the precise role of speechrelated head movement activity is still a controversial issue. In this respect, the head movement analysis introduced here enables investigations about the communicative functions of head movements, including quantitative aspects of all presented dimensions. The following examples of head movement patterns in a dyadic interaction should clarify further possibilities of the analytical procedures, especially in order to qualify the difference of detected head movement patterns during conversation.

The meaning of head movement patterns that are characterized by rotational shifts in position in positive and negative directions can be recognized on the basis of the verbal context (see Step 6). In constant adjacency pairs of utterances ( $\mathrm{A} 1-\mathrm{B} 1$, questions-answers), meaning can be attributed concerning accompanying verbal remarks ("no," "I don't know," "there is no way to do something," etc.). In this respect, head shaking, as a nonverbal form of denial during Subject B's utterance B1, seems to be an appropriate interpretation. An inspection of head-shaking behavior shows that it is usually presented in the rotational dimension only, without participation of other dimensions. However, combined head movement patterns can include parts of exclusive rotational changes. In Figure 7, two different rotational head movements patterns are shown that can be labeled as head shaking that enhances verbal communication. The patterns are characterized by rotational movements that are surrounded by other dimensions or found exclusively (Figures 7A and 7B). On this point, verbal exchange can again serve as a framework for interpretations about the meaning of these different rotational head movement patterns. The subsequent reaction A2 of Partner A may supply an additional indication, because it is required that the partner accepts or rejects Subject B's denial. A detailed analysis of the verbal context of these movement patterns reveals that the subject's head shaking differed in relation to the $s_{\mathrm{c}} \mathrm{b}$ bject's effort to emphasize the intended denial with nonverbal means. This interpretation is suggested because Partner $A$ in $A 2$ is about to accept the denial more often if the subject's head shaking is included in combined head movement patterns than if exclusive rotational head movements are shown. Therefore, within this dyadic interaction, the two distinct head movement patterns of shaking have distinct functional meanings in the course of conversation.

\section{SUMMARY AND DISCUSSION}

The method for analyzing movement behavior presented here has two major advantages: First, replicable results are obtained at each step in the analysis process. 

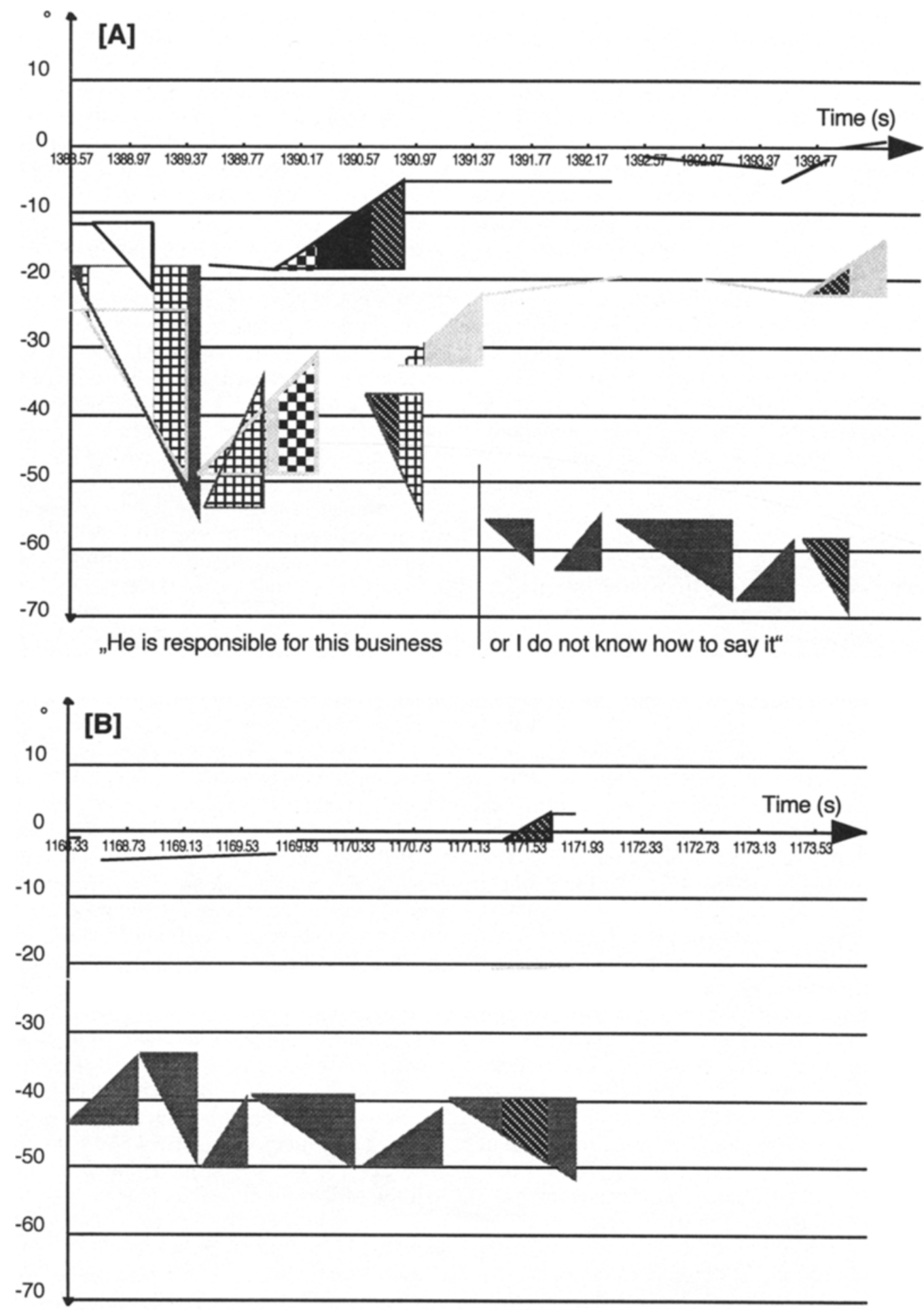

"They said, there are no rooms available in the whole building"

Figure 7. Head shaking during conversation. Panel A: changes in rotational dimension enclosed into more complex head movement pattern. Panel B: changes in rotational dimension. 
Second, the fact that each step is designed as a module aiso makes for a very flexible assessment strategy, thereby facilitating the implementation of additional procedures.

This method is based on a spatial recording of transducer positions. This method of collecting raw data requires attaching small transducers to the parts of the body that bear relevance to the study being conducted. Although this method does restrict the test persons' freedom of movement, it reportedly does so only to a negligible extent. In the future, it would make sense to replace coding units extracted with ultrasonic transducers and receivers with alternative methods - for example, video indexing, provided spatial coordinates can be extracted on the basis of the analysis of data protocols (Abmayr, 1994; Jähne, 1989). Since direct methods of behavior measurement have to map behavior sequences as accurately as possible, information must be available on the positions of reference points on the index person's body, which are noted throughout the course of interaction and can be stored as a time series. At present, this information-a necessary prerequisite for further analysis - can be obtained only by using very complicated technical methods of image analysis (e.g., on the basis of video indexing done with two cameras from different perspectives). Simpler methods make for impressive on-line animation of actual movements and are capable of recognizing certain positions in the course of movement (see Clergue, Goldberg, Madrane, \& Merialdo, 1995; Essa \& Pentland, 1995; Saulnier, Viaud, \& Geldreich, 1995). They usually employ methods of texture recognition or Eigenwert analysis (see Jähne, 1989) and, thus, do without the complicated process of extracting three-dimensional information. Nevertheless, there is little doubt that the rapid development of video technology today is paving the way for inexpensive methods that will, for example, reconstruct picture sequences three dimensionally on the basis of their optical flow. However, it must be taken into account that the transcription of visual information into spatial positions requires an enormous amount of computer programming, which makes it difficult to apply methods of image processing to movement analyses. It is important to note that the procedure for data analysis (Steps 1-6) presented in this paper can be employed with any method of collecting raw data, provided it involves restructuring three-dimensional information in some manner.

Translating raw data into head positions involves, in the first step, transforming spatial transducer positions into meaningful time series of movement sequences. These conversions reduce the time series of sender positions to a time series of bodily relations that are the basis for quantifications of movement patterns. For head positions, the angle between the head and the shoulders are computed at three levels (lateral, sagittal, and rotational; see Frey et al., 1981). The conversion method for head positions suggested here is decoding head movements in terms of three different dimensions that can be combined at any point in time. The computed head movement pat- terns correspond to a measurement of the complete image of any head movement.

In the second step of the analysis, the time series of the angle positions are examined to identify relevant changes. The fact that the onset, size, and termination of a change are noted for each dimension results in further substantial data reduction. The possibilities of adjusting the apparatus allow for the quantification of negligible changes in position. At this point in the analysis, a decision is made as to what is to be regarded as a change in position in the first place. The resolution power used is dependent on the definition chosen so that there is a great likelihood that movement behavior can be measured very accurately.

The third step in the analysis is directed at dividing successive changes in movement into segments. A variable procedure has to be used, since the research efforts to date have failed to yield any conclusive results on the critical length of pauses between elements of movement (see Rosenfeld, 1982). This involves using a time that can be defined to adjust the temporal organization of consecutive movement changes that may be combined into one movement pattern. Concerning the second and third step of the analysis process, the possibility of adjustment in the course of calculation itself can be the focus of attention so that the validity of objective criteria can be tested, for example, by using specific impressions that the observers had. Grouping consecutive head movement changes into head movement patterns is an attempt to move from a molecular approach to decoding small head movements to a more molar approach, which can be used as the point of departure for the empirical analysis of behavior within its situational context.

The fourth step in nonverbal analysis involves the use of methods applied to classify head movement patterns that provide quantitative measures of similarity without labeling them. As a result, by the time these mathematical procedures have been performed, classes of head movement patterns have been set up that are based on critical similarity measures and are independent of observers' interpretations.

Since movement behavior - at least in the area of communication--is constantly being judged and interpreted by people who interact with one another, the functions it serves and its meaning in a given situation can only be clarified by adding two further steps to the analysis process. Context variables, which provide additional information-for example, psychophysiological variables (see Jossen et al., 2000), and verbal analyses (see Käsermann et al., 2000) -on the one hand (Step 5), and which point out the importance of a new research strategy, on the other, should be taken into consideration (Step 6). An exact description of the circumstances in which distinct behavior patterns occur is assessed to give evidence for their functional interpretation - for example, as a symptomatic reflection of biological processes. The behavior that is displayed in social situations presumably serves specific functions that can be systematically recognized by the people one is interacting with. In this respect, move- 
ment patterns would have to be viewed within the setting of comparative situations that enable an examination of communicative functions they possibly serve in interaction. This can be done by embedding movement behavior in the temporal sequence of communication using an experimental-like research strategy (see "contrastive analysis," Käsermann et al., 2000).

In short, the method for recording and analyzing movement behavior described in this paper can be characterized as follows.

First, it provides an objective and replicable quantification of movement patterns, which does not rely on subjective appraisal in the data collection phase of analysis (raw data collection and evaluation, Steps 1-4). Owing to the fact that movement patterns are grouped and analyzed on the basis of quantitative features rather than on the basis of predefined categories, there is the possibility of discovering hitherto unknown head movement patterns.

Second, the interactional context in which movement patterns take place is an integral part of the analysis (Steps 5 and 6). This is based on the underlying assumption that movement behavior cannot be interpreted without including situational characteristics into the analysis. A systematic description of the context in which movement behavior occurs-whether this involves the changing characteristics of a situation (see dose-dependent changes in movement activity in psychopharmacological research; Kane et al., 1994), the communicative framework that lends meaning (see features that accompany the understanding process in conversational sequences; Foppa, 1984) or the comparative analysis of conversational sequences (see contrastive analysis of sequences in the same class of equivalence; Käsermann et al., 2000)forms the framework in which functions and meanings can be attributed to a particular behavior.

This approach to data analysis opens out new vistas in studying nonverbal behavior. As was mentioned earlier in this paper, it can be used in diagnostics and in communication research. In addition, methodologically relevant research can be conducted; for example, objective variables can be derived from subjective movement categories. The relationship between the extraction of movement patterns and the subjective impression of behavior can provide insight into elements that play an important role inone social appraisal process. Moreover, the use of elaborated research designs would enable dealing with various essential research questions that have not received due attention in the field of psychology to date. For iristance, the development of the meaning of movement patterns could be explored by tracing the genesis of a movement pattern (e.g., victory salutes of sports teams) the first time it appears by coincidence, to its systematic interpretation as a sign, and to its emergence as a wellestablished vehicle of meaning. The central prerequisite of such analyses is that all behaviors that are evidenced in conversation are embedded in an interactional context. The method of separating the measurement of movement patterns from interpreting them as specific behaviors makes it possible to appraise aspects of behavior in an unbiased manner and to test the meanings attributed to them in an empirical manner. In this sense, research in the area of nonverbal behavior, which deals with the use of the procedure described in this paper, can be a contribution to the debate about spontaneous and symbolic behavior (Buck, 1982). In addition, processes of "sign formation as a means of communication or the attribution of meaning for somebody else" (Klix, 1993, p. 110) can be examined within the frame of reference of ontogenesis and can be judged from an evolutionary-psychological perspective (Archer, 1992).

\section{REFERENCES}

ABMAYR, W. (1994). Einführung in die digitale Bildverarbeitung. Stuttgart: Teubner.

ALTORFER, A. (1988). Eine Methode zur Untersuchung der interaktiven Bedeutung von nichtverbalen Verhaltensweisen. Sprache \& Kognition, 7, 99-112.

AlTORFER, A. (1999). Nichtverbales Verhalten: Interne Repräsentation und extreme Präsentation. Habilitationsschrift, University of Bern.

Altorfer, A., Goldstein, M. J., Miklowitz, D. J., \& Nuechterlein, K. H. (1992). Stress-indicative patterns of non-verbal behaviour: Their role in family interaction. British Journal of Psychiatry, 161, 103-113.

Altorfer, A., Hirsbrunner, H.-P., \& Käsermann, M.-L. (1990). Messung psychophysiologischer Variablen während Gesprächen: Die Quantifizierung des Volumenpulsgeschehens. Zeitschrift für Psychologie, 198, 293-308.

Altorfer, A., Jossen, S., \& Würmle, O. (1996). Non-verbal behaviour patterns of schizophrenic patients: Analysis, empirical findings, and perspectives for therapeutic interventions. Schizophrenia Research, 18, 120.

Altorfer, A., Jossen, S., \& Würmle. O. (1997). Eine Methode zur zeitgenauen Aufnahme und Analyse des Bewegungsverhaltens. Zeitschrift für Psychologie, 205, 83-117.

Altorfer, A., Käsermann, M.-L., \& Hirsbrunner, H.-P. (1991). Erhebung und Analyse des Fingerpulsvolumens auf der Basis einer quasi-kontinuierlichen Messung von Periode und Amplitude. Zeitschrift für Differentielle \& Diagnostische Psychologie, 12, 33-41.

Altorfer, A., KäsermanN, M.-L., \& Hirsbrunner, H.-P. (1998). Arousal and communication: I. Relationship between nonverbal behavioral and physiological indices of the stress response. Journal of Psychophysiology, 12, 40-59.

Altorfer, A., Merlo, M. C. G., \& Jossen, S. (1997). Head movement patterns of schizophrenic patients during drug treatment: Communicative disorder or expression of side effects. Schizophrenia Research, 24, 263.

Altorfer, A., Merlo, M. C. G., Käsermann, M.-L., Jossen, S., \& HOFER, H. (1998). Head movement behavior of early-psychotic patients during social interaction: Psychopathological phenomenon or side effect of neuroleptic drug treatment. Paper presented at the Second Internet Congress on Psychiatry, University of Tübingen. Available: http://www.medizin.uni-tuebingen.de/ukpp/congress/newcongress/ $\mathrm{m} 4 . \mathrm{html}$

American Psychiatric Association (1994). Diagnostic and statistical manual of mental disorders: DSM-IV (4th ed.). Washington, DC: Author.

ARCHER, J. ( 1992). Ethology and human development. New York: Harvester Wheatsheaf.

BöHLEN, R., \& LiechTi, P. (1992). Benutzerhandbuch menschliche Bewegungen automatisch erfasst und ausgewertet. Unveröffentlichte Diplomarbeit, Ingenieurschule Burgdorf.

Buck, R. (1982). Spontaneous and symbolic nonverbal behavior and the ontogeny of communication. In R. S. Feldman (Ed.), Development of nonverbal behavior in children (pp. 29-62). New York: Springer-Verlag.

Clergue, E., Goldberg, M., Madrane, N., \& Merialdo, B. (1995). 
Automatic face and gestural recognition for video indexing. In M. Bichsel (Ed.), International workshop on automatic face- and gesturerecognition (pp. 110-115). Zurich: MultiMedia Laboratory.

DUdA, R. O., \& HART, P. E. (1973). Pattern classification and scene analysis. New York: Wiley.

EKMAN, P., \& FrIESEN, W. (1969). The repertoire of nonverbal behavior: Categories, origins, usage, and coding. Semiotica, 1, 49-98.

ESHED RoBotec, INC. (1990). Instruction Manual V-Scope Systems, VS100 and VS-110PRO Rev. 1.3. Princeton, NJ: Author.

Essa, I. A., \& Pentland, A. (1995). Facial expression recognition using visually extracted facial action parameters. In M. Bichsel (Ed.) International workshop on automatic face- and gesture-recognition (pp. 35-40). Zurich: MultiMedia Laboratory.

FopPA, K. (1984). Redeabsicht und Verständigung. Manuskripte, 23 (84, Heft der Gesamtfolge), 73-76.

Frey, S., Hirsbrunner, H. P., Pool, J. A., \& Daw, W. (1981). Das Berner System zur Untersuchung nonverbaler Interaktion: I. Die Erhebung des Rohdatenprotokolls. In P. Winkler (Ed.), Methoden der Analyse von Face-to-Face Situationen (pp. 203-236). Stuttgart: Metzler.

Frey, S., \& Pool, J. A. (1979). Vom Bildschirm zum Datenprotokoll. Semiotik, 1, 193-209.

HaDAR, U. (1991). Body movement during speech: Period analysis of upper arms and head movements. Human Movement Science, 10, 419-446.

Hadar, U., Steiner, T. J., Grant, E. C., \& Rose, F, C. (1984). The timing of shifts of head postures during conversation. Human Movement Science, 3, 237-245.

Haralick, R. M., \& Shapiro, L. G. (1992). Computer and robot vision (Vol. I). Reading, MA: Addison-Wesley,

HaRalick, R. M., \& ShapIRo, L. G. (1993). Computer and robot vision (Vol. II). Reading, MA: Addison-Wesley.

Hirsbrunner, H. P., Florin, A., \& Frey, S. (1981). Das Berner System zur Untersuchung nonverbaler Interaktion: II. Die Auswertung von Zeitreihen visuell-auditiver Information. In P. Winkler (Ed.), Methoden der Analyse von Face-to-Face Situationen (pp. 237-268). Stuttgart: Metzler.

Hirsbrunner, H. P., Frey, S., \& Crawford, R. (1987). Movement in human interaction: Description, parameter formation and analysis. In A. W. Siegman \& S. Feldstein (Eds.), Nonverbal behavior and communication (2nd ed., pp. 99-141). Hillsdale, NJ: Erlbaum.

JäHNE, B. (1989). Digitale Bildverarbeitung. Berlin: Springer-Verlag.

Jossen, S. (1996). Die Analyse von Kopfbewegungen während Gesprächen. Lizentiatsarbeit, Institut für Psychologie, University of Bern.

Jossen, S., Käsermann, M.-L., Altorfer, A., Foppa, K., ZimmerMANN, H., \& HirsbrunNer, H.-P. (2000). The study of emotional processes in communication: II. Peripheral blood flow as an indicator of emotionalization. Behavior Research Methods, Instruments, \& Computers, 32, 47-55.

Kane, J. M., Schooler, N. R., Marder, S. R., Simpson, G. M., \& CASEY, D. E. (1994). Methods for clinical evaluation of pharmacological treatment of schizophrenia. In R. F. Prien \& D. S. Robinson (Eds.), Clinical evaluation of psychotropic drugs: Principles and guidelines (pp. 345-372). New York: Raven Press.

KäSERMANN, M.-L. (1983). Form und Funktion schizophrener Sprachstörungen. Sprache \& Kognition, 3, 132-147.

KäSERMANN, M.-L. (1995). Emotion im Gespräch: Auslösung und Wirkung. Bern: Hans Huber.

KäSERmann, M.-L., \& Altorfer, A. (1989). Family discourse: Situations differing in degree of stress and their physiological correlates. British Journal of Psychiatry, 155(Suppl. 5), 136-143.

KäSermanN, M.-L., \& Altorfer, A. (1990). Was uns in Gesprächen aufregt ... Störendes kommunikatives Verhalten und seine Wirkung auf den Gesprächspartner. In K. Grawe, R. Haenni, N. Semmer, \& F. Tschan (Eds.), Über die richtige Art Psychologie zu treiben (pp. 136143). Göttingen: Hogrefe.

KäSermanN, M.-L., \& Altorfer, A. (1994). Communicative stress and coping in schizophrenic and healthy persons. In A. Beigel, J. J. Lopez Ibor, \& J. A. Costa e Silva (Eds.), Past, present and future of psychiatry: IX World Congress of Psychiatry (pp. 451-455). Singapore: World Scientific Publishing.
Käsermann, M.-L., Altorfer, A., FopPa, K., Jossen, S., \& ZimmerMANN, H. (2000). The study of emotion in communication: l. Measuring emotionalization in everyday face-to-face communicative interaction. Behavior Research Methods, Instruments, \& Computers, 32, 33-46.

Käsermann, M.-L., Altorfer, A., \& Hirsbrunner, H.-P. (1998). Arousal and communication: II. Courses of physiological activation during different types of interaction. Journal of Psychophysiology, 12, 60-75.

KLIX, F. (1993). Erwachendes Denken: Geistige Leistungen aus evolutionspsychologischer Sicht. Heidelberg: Spektrum Akademischer Verlag.

PARsons, O., \& Nixon, S. J. (1993). Behavioral disorders associated with central nervous system dysfunction. In P. B. Sutker \& H. E. Adams (Eds.), Comprehensive handbook of psychopathology (2nd ed., pp. 689-733). New York: Plenum.

QUINLAN, P. (1991). Connectionism and psychology. A psychological perspective on new connectionist research. New York: Harvester Wheatsheaf.

RosenfelD, H. M. (1982). Measurement of body motion and orientation. In K. R. Scherer \& P. Ekman (Eds.), Handbook of methods in nonverbal behavior research (pp. 199-286). Cambridge: Cambridge University Press.

RosenthaL, R. (1982). Conducting judgment studies. In K. R. Scherer \& P. Ekman (Eds.), Handbook of methods in nonverbal behavior research (pp. 287-361). Cambridge: Cambridge University Press.

Sacks, H., Schegloff, E. A., \& Jefferson, G. A. (1974). A simplest systematics for the organization of turn-talking for conversation. Language, 50, 696-735.

Saulnier, A., Viaud, M. L., \& Geldreich, D. (1995). Real-time facial analysis and synthesis chain. In M. Bichsel (Ed.), International workshop on automatic face- and gesture-recognition (pp. 86-91). Zurich: MultiMedia Laboratory.

SCHEgloff, E. A., \& SACKS, H. (1973). Opening up closings. Semiotica, 7, 289-327.

SCHERER, K. R., \& WALLBOTt, H. G. (1985). Analysis of nonverbal behavior. In T. A. van Dijk (Ed.), Handbook of discourse analysis: Vol. 2. Dimensions of discourse (pp. 199-230). London: Academic Press.

Simpson, G. M., \& ANGUS, J. W. S. (1970). A rating scale for extrapyramidal side effects. Acta Psychiatrica Scandinavica, 212, 11-19.

TrYON, W. W. (1991). Activity measurement in psychology and medicine. New York: Plenum.

WALLBOTT, H. G. (1980). The measurement of human expression. In W. von Raffler-Engel (Ed.), Aspects of nonverbal communication (pp. 203-228). Amsterdam: Swets \& Zeitlinger.

\section{NOTES}

1. The V-Scope hardware is distributed by Eshed Robotec Inc., 445 Wall Street, Princeton, NJ 08450. The cost of the system with four transducers for head movement analysis, including easy-to-use menu and icon-driven software (for Windows) to control hardware and to record raw data (positions of each sender in three dimensions), is about $\$ 7,500$.

2. The software (MS-DOS 3.3 and higher, Windows 3.1, Windows 95 , Windows 98, Windows NT) for the calculation of the angle positions of the head in the dimensions lateral, sagittal, and rotational, as weli as of intensities of head movement activity can be obtained from the authors for a nominal fee $(\$ 50)$ by e-mail.

3. The procedures for extraction, analysis, and categorization of head movement patterns are implemented in a further software package (for Apple Macintosh [Power Macintosh, G3, MacOS 8.6] or for PC Systems [MS-DOS 3.3 and higher, Windows 3.1, Windows 95, Windows 98 , Windows NT]). This software package can be obtained from the authors for a nominal fee ( $\$ 50)$ by e-mail.

(Manuscript received December 18, 1998; revision accepted for publication October 28,1999 .) 